\title{
HYDROPONICS FOR ECONOMIC COMMUNITY DEVELOPMENT
}

\author{
Singmin Johanes Lo and Aty Herawati \\ Universitas Mercu Buana Jakarta, Indonesia.
}

\begin{abstract}
This paper is about empowering the economy for community development through hydroponics cultivation. Preactivity data on partner community were collected by on site interviews and field observation. From the data analysis, it was suggested to do hydroponics farming for partner community. Training on hydroponics and how to grow plants hydroponically was given. The knowledge and skills about food crops produced by hydroponics cultivation were given through training. It was done by giving interactive lecture and on site practice on November 11, 2018 to fifteen participants, mostly homemakers, from Desa Anggadita, East Karawang, West Java as partner community. All participants were involved in group discussion, and were very happy for the training. They got the knowledge on hydroponics. They knew the many economic and social benefits in doing hydroponics farming. Having the knowledge and skills needed for hydroponics farming and couple with partner community enthusiasms, they were challenged to do hydroponics farming on their front or backyards. The partner community can soon provide healthy food, herbs medicine, and flowers products for their own use and for commercial purposes, eventually. Partner community awareness on hydroponics farming will also contribute to healthy community lifestyle, greener environment, and more sustainable earth.
\end{abstract}

Keywords: Hydroponics, Community, Training, Economic, Healthy, Green, Sustainable

\section{INTRODUCTION}

\section{A. BACKGROUND SITUATION}

There is a strong need in the part of the Indonesian government to empower the economy and social of the people through sustainable community development. Mercu Buana University is required by the Ministry of Research and Higher Education to be involved in the community development. Pre-activity data on partner community were collected by on site interviews and field observation. From the data analysis, it was concluded that hydroponics farming was one of the suitable activities chosen for community development since people living in urban areas do not have the luxury of large areas of soils for farming. They live in houses with little or no soils for crops farming. A few of them who do farming usually optimize their limited front or backyard areas for planting food products, such as vegetables, fruits, or herbs for medicine, and other food crops for their own day to day consumptions. Some others use their limited soils to plant flowers to beautify their homes. There is a need to encourage urban community to make use their front or backyards soils to cultivate highly economic value of crops and plants (Treftz, 2016). Growing certain huge oxygen supply plants is very useful for providing urban oxygen and reducing pollutions as well. The goals of having partner community to do crops hydroponics are to empower community economy, healthy life style, and social cooperation towards community sustainable development.

Urban hydroponics farming has become a global trend (Barbosa et al., 2015). It gives ample benefits for people live in town since some of the food products, herbs medicine, and flowers can be obtained readily in fresh condition without going through long distance transport from rural areas. By urban farming, any crops quality degradation can be reduced substantially. There are some techniques in urban planting, for example hydroponics, aeroponics, aquaculture, vertical farming, polybags and pots farming. One technique which is discussed in this study is hydroponics cultivation.

Hydroponics cultivation is a technique of growing plants without soil, but need supply of nutrients, water and an inert medium (Resh and Howard, 2012). The supplied of nutrients in the form of solution consist of nitrogen $(\mathrm{N})$, phosphor $(\mathrm{P})$, potassium $(\mathrm{K})$, sulfur $(\mathrm{S})$, calcium $(\mathrm{Ca})$, and magnesium $(\mathrm{Mg})$ as macronutrients. In addition to macronutrients, plants also need iron $(\mathrm{Fe})$, chlorine $(\mathrm{Cl})$, manganese $(\mathrm{Mn})$, boron $(\mathrm{B})$, zinc $(\mathrm{Zn})$, copper $(\mathrm{Cu})$, and molybdenum (Mo) in very small amounts as micronutrients (Resh and Howard, 2012). Hydroponics is considered a modern technique of corps farming. In hydroponics plants, the macronutrient and micronutrient solution is needed by the plant roots to absorb the minerals and water (Gruda, 2009). Food crop using hydroponics technique has a lot of added values. It uses limited pesticide and other harmful materials unhealthy for human consumption (Barbosa, et al., 2015). Hydroponics cultivation technique does not require soil for farming but can produce higher yields than soil grown farming throughout the year (Gruda, 2009). Besides that 
hydroponics technique quickens harvest time, uses more accurate measured on needed nutrients while yielding better quality and quantity (Barbosa et al., 2015).

\section{B. PROBLEM IDENTIFICATION}

The object of this study is a small town, Anggadita, Klari county, East Karawang, West Java. It is located 28 $\mathrm{km}$ east of Jakarta. Some problems had been identified in this location. They are as follows:

1. There are not enough soils for soil farming in that community.

2. There are some problems with the availability of clean and fresh food crops products in the traditional market.

3. Prices of food crops products in the supermarket are high.

4. There is limited time to do traditional soil farming for food products.

5. There is little awareness of the people in the community to cultivate their front or backyards for food crops farming.

6. There is lack of knowledge and skills in hydroponics farming of food, herbal medicine, and flowers products.

\section{OBJECTIVES AND OUTCOMES}

\section{A. OBJECTIVES}

The objective of this study is to improve the knowledge and the ability of the people in Anggadita community to do plants farming by hydroponics systems in their own front or backyards. Therefore, some important concepts on hydroponics farming need to be learned and acquired by the people living in the community.

There are six basic systems on hydroponics farming, i.e. Wick system, Water Culture system, Flood and Drain system, Drip Irrigation system, Nutrient Film Technique (NFT), and Aeroponics system; however, only the simplest system of hydroponics farming, i.e. the Wick system was suggested to the community partner. The Wick system (see Figure 1) is the easiest of hydroponics systems and a passive system. It means there is no movement of plants. Nutrient solution is absorbed by plant medium by using wicks from a nutrient solution container. The nutrient solution is absorbed due to capillary force into plant medium. The roots of the plant then absorbed the nutrient solution. The plant medium consists of inert medium, such as perlite, vermiculite, pro-mix, or coconut coir (Resh and Howard, 2012).
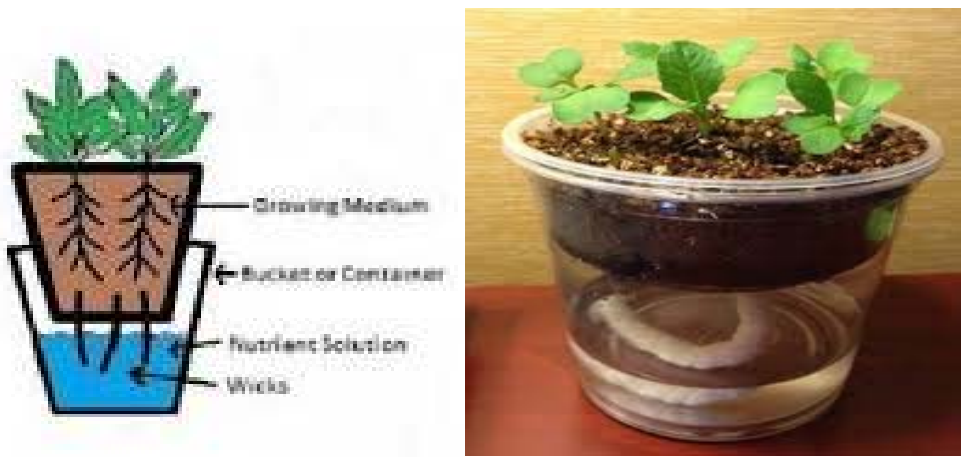

Figure 1. Hydroponics with Wick system

Perlite (Figure 2) is a unique type of volcanic glass with high water content. It is lightweight, easy to handle, clean and has no odor with $\mathrm{pH}$ of 6.6 to 7.5

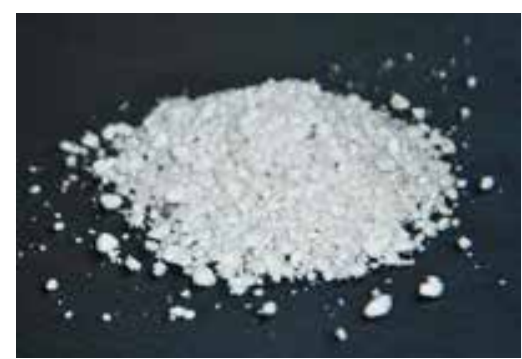

Figure 2. Perlite

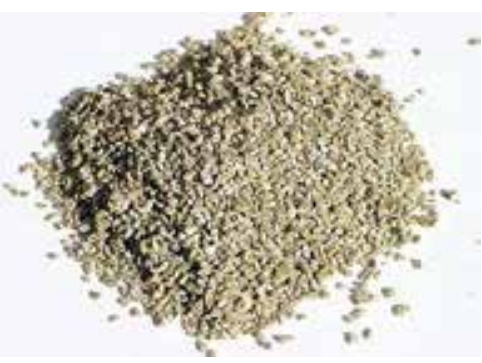

Figure 3. Vermiculite 
Vermiculite (Figure 3) is a compressed dry flake of sand (silicate material) which is absorptive and spongy. The color of vermiculite is a golden brown to a dark brown. When water is added to vermiculite, the flakes expand into a worm-like shape and act like an absorbing sponge. It interacts with potassium $(\mathrm{K})$, calcium $(\mathrm{Ca})$ and magnesium $(\mathrm{Mg})$ in soil. Vermiculite has a neutral $\mathrm{pH}$ of 7.0. It is used is to raise the plants $\mathrm{pH}$ slightly. Vermiculite absorbs more water than perlite, it does not aerate the soil as well. This means less oxygen for plant roots. Someone should not use vermiculate for plant media when growing plants that do not need damp soil, since it may cause the plants suffer from root rot. (www.epicgardening.com).

Hydroponics plants need enough air, water, and nutrients for the roots' food supply. A healthy hydroponics plant should be able to absorb and channel water, does not change the water $\mathrm{pH}$ and color, and does rot not easily. It is suggested to always monitor the concentration of the nutrient solution. Accepted concentration of nutrient solution is about $2 \mathrm{mS} / \mathrm{cm}$. To monitor the concentration of the nutrient solution one uses electrical conductivity (EC) (Song, et al. 2019). An EC meter is used as a tool for measuring the strength of hydroponics nutrient formulas. The measurement can also be done manually by observing the thickness of the solution and the changing color of the plant's leaves. The yellowish color of the leaves indicates that the plant is under nourishment. Abrupt increase in EC reading shows that there is metabolism problem with the plant, especially for grown plant. Abrupt decrease in EC reading causes plant leaves to become stiff and has difficulty in growing due to lacking of nutrients in the solution. There should not be any immediate increase or decrease of EC readings since it is not good for the hydroponics plant. The supply of nutrients in solution can also be detected by measuring the $\mathrm{pH}$ solution. An acceptable acidity for plant absorption of nutrient solution is a $\mathrm{pH} 6.3$ to 6.5 (Roberto, 2004).

Controlling on plants disturbing organisms and plants diseases, monitoring concentration and $\mathrm{pH}$ nutrient solution, and the speed of nutrients absorption are very important for plants caring. It is suggested not to use pesticide or insecticide in eradicating plants diseases, but to do it manually in order to eliminate human carcinogenic threats.

\section{B. OUTCOMES}

The expected outcomes of this study are as follows:

1. Increasing number of people are able to do hydroponics farming.

2. People are becoming interested in crops farming by hydroponics cultivation.

3. People in Anggadita, the partner community are doing crops farming using hydroponics cultivation.

\section{METHODE}

\section{A. ACTIVITY AND PARTICIPANTS}

The delivery of the training was carried out on Sunday, November 11, 2018, from $6.00 \mathrm{am}$ to $11.00 \mathrm{am}$. It was done at a public town hall in Anggadita, Klari County, East Karawang, West Jawa. The participants for this training were the partner community, especially the homemakers. There were fifteen people attended this training.

\section{B. METHOD OF EXECUTION}

The training execution method was in a structured form. The explanation of the training materials was in logical and systematic way, but in day to day simple language. It was focused on understanding on how to do hydroponics farming with some easy to follow theoretical explanations. On site demonstration was also given to show on step by step doing hydroponics farming.

The execution steps for hydroponics farming on maintenance and caring refers to Jones (2005). One must pay attention when taking care of hydroponics plants. The plants caring are as follows:

1. In hydroponics farming, the use of Total Dissolved Solids (TDS) meter and $\mathrm{pH}$ meter are very crucial. TDS meter gauged the minerals, salts, metals, cations, and anions, and other materials contents dissolved in water. Hydroponics plants will grow better if the nutrients parts per-million (ppm) in solution is fit with the plants. It is measured by TDS meter, i.e. the thicker the nutrient solution, the higher the TDS meter reading. The $\mathrm{pH}$ meter measures the $\mathrm{pH}$ of the nutrient solution. The right $\mathrm{pH}$ reading of the solution should be 6.3 to 6.5 (Roberto, 2004). The reading of both TDS meter and $\mathrm{pH}$ meter should be taken daily for having healthy hydroponics plants.

2. There should be controlled on Plant Disturbing Organisms (PDO), such as insects, bug, pest, vermin, weed, and other plants diseases. The control should be done manually. Avoid using insecticide, pesticide, and other harmful chemical. 
3. One should monitor the nutrient solution conduits at least three times daily. The clogged in nutrient solution conduits will kill the whole hydroponics plants altogether.

4. One should always check the pumps to be in good condition and the water pots for the nutrient solution not short of water.

\section{RESULTS AND DISCUSSION}

\section{A. EXECUTION}

This activity was conducted as one of the Community Development programs by Mercu Buana University Graduate School Program Masters in Management as required by Ministry of Research and Technology and Higher Education, called "Tri Dharma Perguruan Tinggi'.

The training, group discussion, and on site demonstration were carried out well as planned. There were fifteen participants, mostly homemakers, attended this hydroponics farming training. The training was given through interactive lecture, question and answer session, and case study group discussion, as well as on-site demonstration.

\section{B. MATERIALS AND EQUIPMENT}

Training materials were given in the beginning. They were about the theory and cases related to hydroponics farming. The trainer presented the material using power-point software interactively, followed by case discussions in groups. Equipment, necessary for on-site demonstration were brought. Finally, on site demonstration showing how to do simple Wick system hydroponics farming was done,

\section{EVALUATION}

The evaluation conducted at the end of the training revealed that the participants were happy with the training. Although some parts of the lecture were difficult to follow, especially about the technical and chemical parts, the major parts on knowledge and skills about hydroponics farming were understood. They said that the training was useful. They could see the many benefits hydroponics farming can give for them and community development in terms of healthy living, economic empowerment, and social unity. Some of them wanted to have follow-up program on this hydroponics farming. The success of this training was due to good cooperation and collaboration efforts from all parties, the team from the Mercu Buana University Community Development and the Partner Community officers and participants.

\section{DISCUSSION}

This community development program was first started by doing field survey, interviews, and direct observations on what could be needed by the Anggadita community. From the preactivity data gathered, the people needed hands on training on hydroponics cultivation. They wanted to know and learn about hydroponics. They wanted to have the knowledge and skills to do hydroponics farming.

Related to the problem identification discussed earlier, the solutions given were as follows:

1. By doing hydroponics farming, people in the community will be able to get fresh and clean and affordable food products.

2. Through a suitable training, people in the community will understand and gain the knowledge and skills needed fo doing hydroponics farming successfully.

\section{CONCLUSION}

The individuals, who participated in the hydroponics training, were able to express their ideas and creativity; however, they needed more time to digest and understand the "hard stuffs" on technical terms. The participants' mind-sets were flexible and open to learning on new things. Some participants were active during the lecture and group discussions making the class alive and dynamics. All participants agreed that the training was interesting and useful. There were many new things learned from the training.

The materials given in the training were designed for the participants so that they were able to do their own hydroponics farming. After attending the training, the participants agreed that they knew what hydroponics cultivation was. They acquired the knowledge and skills on how to do hydroponics farming. The training materials were useful and doable. 
Through this activity, the goals to build communication and relationship and to improve community development by the university "Tri Dharma Perguruan Tinggi" were achieved. It was suggested that the time duration for this training could be added since there were a lot of questions being asked and the time for case study discussions were too short. The participants were very eager to learn on hydroponics farming. They wanted to know more about which food, herbs medicine, and flowers crops products suitable for them.

\section{REFERENCES}

Barbosa, G., Gadelha, F., Kublik, N., Proctor, A., Reichelm, L., Weissinger, E., Wohlleb, G.M. and Halden, R.U. (2015). "Comparison of land, water, and energy requirements of lettuce grown using Hydroponics vs Conventional Agricultural Methods", International Journal of Environmental Research and Public Health, Vol. 12 No. 6, pp. 6879-6891.

Gruda, N. (2009). "Do soilless culture systems have an influence on product quality of vegetables?" Journal of Applied Botany and Food Quality 82:141-147.

Jones, J.B. (2005). Hydroponics: A practical guide for the soilless grower. Boca Raton, FL: CRC Press.

Resh, H.M. and Howard, M. (2012). Hydroponics Food Production: A Definitive Guidebook for the Advanced Home Gardener and the Commercial Hydroponics Grower, 6th Ed., EUA, Santa Bárbara, CA.

Roberto K. (2004). How-To Hydroponics. Fourth Edition. Futuregarden Press. New York.

Song, J.X., Xu, L, He, D.X., Tuskagoshi S, Kozai T, and Shinohara Y. (2019). "Estimating EC and ionic EC contribution percentage of nutrient solution based on ionic activity". Int J Agric \& Biol Eng.; 12(2): 42-48.

Treftz, C. and Omaye, S. T. (2016). "Hydroponicss: potential for augmenting sustainable food production in non-arable regions." Nutrition \& Food Science. Vol. 46 No. 5, pp. 672-68.

www.epicgardening.com 